* Doutora nas relações sociais - direito civil - pela UFPR Universidade Federal do Paraná, graduação e mestrado em direito civil pela UEM Universidade Estadual de Maringá, pesquisadora do ICETI, professora da graduação e Programa de Mestrado e Doutorado da UNICESUMAR, membro do IBDFAM e o IAP \ Instituto dos Advogados do Paraná. Advogada. E-mail: cleidefermentao@gmail.com.

** Mestranda em Ciências Jurídicas pelo Centro Universitário de Maringá - UniCesumar, com enfoque nos Direitos da Personalidade e seu alcance na contemporaneidade. Bolsista do Programa de Suporte à PósGraduação de Instituições de Ensino Particulares (PROSUP/ CAPES). Membra do grupo de Pesquisa "Proteção Integral da Pessoa: Interações dos Direitos Humanos, dos Direitos Fundamentais e dos Direitos da Personalidade". Graduada no Curso de Direito pela Pontifícia Universidade Católica do Paraná (2014-2018). Advogada. E-mail: annaefernandes@gmail.com.

\section{A Mediação Como Tratamento Nos Conflitos IntersubJetivos Em Defesa Da Dignidade Humana}

\author{
Mediation As Treatment In Intersubjective Conflicts \\ In Defense Of Human Dignity
}

\section{Cleide Aparecida Gomes Rodrigues Fermentão* Ana Elisa Silva Fernandes**}

Como citar: FERMENTÃO, Cleide Aparecida Gomes Rodrigues; FERNANDES, Ana Elisa Silva. A MEDIAÇÃO COMO TRATAMENTO NOS CONFLITOS INTERSUBJETIVOS EM DEFESA DA DIGNIDADE HUMANA. Revista do Instituto de Direito Constitucional e Cidadania - IDCC, Londrina, v. 4, n. 2, p 93-108, dez, 2019. ISSN: 2596-0075.

https://doi.org/10.48159/revistadoidcc.v4n2.fermentao.fernandes

Resumo: O presente estudo propõe-se a analisar os conflitos intersubjetivos sob a ótica dos direitos fundamentais, especialmente a dignidade humana. A contemporaneidade está sendo marcada pela individualidade e pela liquidez, sendo que nada, inclusive os relacionamentos, são feitos para durar por muito tempo. Como consequência, as crises e os conflitos nas relações entre indivíduos crescem exponencialmente, sendo no ambiente de conflito que a dignidade do outro é desconsiderada, e a individualidade é acentuada. Como forma de promoção da dignidade humana nas relações, propõe-se o tratamento adequado aos conflitos de interesses, sendo a mediação o enfoque no presente trabalho. Assim, a mediação, em crescimento no Brasil, possui técnicas que proporcionam aos indivíduos reflexões a respeito da crise e a consideração do outro como pessoa dotada de dignidade e valores, com o objetivo de humanização o conflito, promovendo a dignidade humana e os direitos fundamentais.

Palavras-chave: Direitos Fundamentais. Dignidade Humana. Conflitos Intersubjetivos. Tratamento ao Conflito.

Abstract: The present study proposes to analyze intersubjective conflicts from the point of view of fundamental rights, especially human dignity. Contemporaneity is marked by individuality and liquidity, and nothing, including relationships, is made to last for long. As a consequence, crises and conflicts in relationships between individuals grow exponentially, and in the environment 
of conflict the dignity of the other is disregarded, and individuality is accentuated. As a way of promoting human dignity in relationships, it is proposed to treat conflicts of interest appropriately, and mediation is the focus of this work. Thus, mediation, growing in Brazil, has techniques that provide individuals with reflections about the crisis and the consideration of the other as a person endowed with dignity and values, with the goal of humanizing conflict, promoting human dignity and fundamental rights.

Key-words: Fundamental rights. Human dignity. Intersubjective conflicts. Treatment to Conflict. 


\section{INTRODUÇÃO}

O presente estudo tem como objetivo principal demonstrar que o tratamento adequado para a solução de conflitos intersubjetivos é a mediação, por tratar-se de instrumento de promoção da dignidade humana. Isso porque a dignidade humana, em sua dimensão relacional (ser para os outros), em virtude do individualismo na pós-modernidade, acha-se violada em razão dos conflitos que surgem nos relacionamentos interpessoais. Assim, o tema em análise é de extrema importância, pois a dignidade é elemento essencial da vida humana, portanto, deve ser respeitada e protegida pelo Estado e por toda a comunidade.

Os conflitos intersubjetivos, com crescimento exponencial - consequência da pósmodernidade, em que os relacionamentos são breves e as pessoas descartáveis - tem origem em diversos ambientes . À vista disto, destaca-se o desrespeito a valores intrínsecos ao ser, como a dignidade humana. Portanto, é especialmente necessária a compreensão que os conflitos devem ser geridos de forma a promover a dignidade, especialmente nas relações continuadas.

O tratamento adequado aos conflitos de interesses por intermédio da mediação, que pode ser entendida como técnica autocompositiva que incentiva as partes a enfrentarem o conflito como uma oportunidade de crescimento e desenvolvimento, por meio de técnicas aplicadas pelo mediador, promove o respeito à dignidade humana. Assim, pode ser a mediação um instrumento de proteção da dignidade humana.

A presente pesquisa buscará respostas à seguinte problematização: a mediação constitui instrumento de tratamento de conflitos em defesa da dignidade humana?

Para buscar as respostas ao questionamento apresentado, a presente pesquisa utilizará o método indutivo, por intermédio de pesquisas bibliográficas, e tem como pretensão levar o leitor à consciência sobre os efeitos dos conflitos intersubjetivos à dignidade da pessoa humana e a mediação como proposta de transformação dos conflitos;

\section{CONFLITOS INTERSUBJETIVOS}

A análise do conflito como termo jurídico perpassa por todas as áreas do Direito. Conflictus ou confligere, no latim, possui o sentido de oposição, divergência, desacordo, enfrentamento e antagonismo. ${ }^{1}$ Em sua definição jurídica, revela o "entrechoque de ideias ou de interesses, em virtude do que se forma o embate ou a divergência entre fatos, coisas ou pessoa." Para o Direito, existe conflito quando há uma pretensão resistida ou insatisfeita ${ }^{3}$, sendo o processo judicial um dos instrumentos capazes direcionar na busca de soluções, e que por muitos anos foi considerado o único método formal de resolução de conflitos. ${ }^{4}$

$\mathrm{O}$ conflito pode ter origem em diversos ambientes. Nesse sentido, Zygmunt Bauman ilustra que na sociedade pós-moderna vive-se um processo de "liquefação", inclusive, nas relações interpessoais (meio social em que surgem as situações conflituosas). Assim, a respeito da sociedade pós-moderna, o autor sociólogo explica que 
Estamos agora passando da fase 'sólida' da modernidade para a fase 'fluida'. E os 'fluidos' são assim chamados porque não conseguem manter a forma por muito tempo, e a menos que sejam derramados num recipiente apertado, continuam mudando de forma sob a influência até mesmo das menores forças. ${ }^{5}$

O processo de "liquefação" da realidade, em que nada é feito para durar, especialmente as relações, é identificado pelo aumento de crises e conflitos entre os indivíduos, em que se destaca o desrespeito a valores intrínsecos ao ser, como a dignidade humana. É nesse sentido que se entende a necessidade de gerir os conflitos principalmente os que têm origem em relações continuadas.

Por relação continuada, entende-se aquela em que as partes já possuíam um convívio anterior à ao momento de crise e em razão das próprias particularidades do conflito, este vínculo permanecerá. A esse respeito, uma relação continuada pode ter diversas naturezas e advir de inúmeros núcleos de relacionamento, entretanto, o ambiente em que mais se identifica um histórico entre as partes e manutenção deste, é o familiar. ${ }^{6}$ Nos conflitos em que há um vínculo de continuidade entre as partes, propõem-se a utilização de técnicas oportunizem, além da resolução, a humanização do conflito, identificando os reais interesses, restabelecendo a comunicação entre os indivíduos e o proporcionando o empoderamento dos sujeitos para que sejam capazes de chegar a uma resolução que seja sustentável no futuro, como forma de promoção da dignidade humana. ${ }^{7}$

Ricardo Deutsch ${ }^{8}$ explica que "existem alguns fatores que interferem no curso do conflito, como por exemplo, a cultura e o meio em que os indivíduos convivem". Nesse sentido, retomase a ideia desenvolvida pelo sociólogo Zygmunt Bauman, de que a vida líquida é marcada pela impossibilidade de se manter a forma ou permanecer preservada por muito tempo, ${ }^{9}$ pelo individualismo que enfraquece os relacionamentos interpessoais e pela noção de que as pessoas são reduzidas a coisas e relacionamentos a bens de consumo. De acordo com Edgar Morin, diante de determinado conflito, os indivíduos tendem a atribuir ao outro a responsabilidade pela situação ${ }^{10}$ e, por força do individualismo, desconsideram a identidade da outra pessoa, o que promove a violência na relação ${ }^{11} \mathrm{e}$ o desrespeito à dignidade humana.

A noção Kantiana concebe a dignidade em função do homem singular, limitado à sua esfera individual. Também, compreende a dignidade em sua dimensão intersubjetiva e considera a existência humana em relação com outros indivíduos (ser para os outros ${ }^{12}$ ) "constituindo uma

5 BAUMAN, Zygmunt. Identidade. Rio de Janeiro: Zahar, 2005, p. 57-58.

6 GORETTI, Ricardo. Mediação e acesso à justiça. Salvador: Editora JusPodivm, 2016, p. 41-42.

7 GORETTI, Ricardo. Mediação e acesso à justiça. Salvador: Editora JusPodivm, 2016, p. 43.

8 DEUTSCH, Morton. The Resolution of Conflict: Constructive and Destructive Processes. New Haven and London: Yale University Press, 1973.

9 BAUMAN, Zygmunt. Vida líquida. Rio de Janeiro: Zahar, 2009, p. 7. Apud GORETTI, Ricardo. Mediação e acesso à justiça. Salvador: Editora JusPodivm, 2016, p. 43.

10 MORIN, Edgar. A educação e a complexidade: os setes saberes e outros ensaios. 6 ed. Rio de Janeiro: Cortez, 2013, 97-98.

11 GORETTI, Ricardo. Mediação e acesso à justiça. Salvador: Editora JusPodivm, 2016, p. 125-126.

12 A respeito da realidade ontológica do homem em que a pessoa é um ser em si mesmo, ser com os outros e para os outros, Joaquín Ferrer Arellano explica que "o homem é pessoa em função de toda a comunidade, e conquista a sua personalidade, isto é, o mérito e o valor da sua pessoa plenamente desenvolvida, na comunidade e pela comunidade. [...] Só neste tecido de relações intersubjetivas chega o homem a ser pessoa e conquistar uma personalidade (no sentido de perfeição pessoal).” (ARELLANO, J. Ferrer. EI Misterio de los Orígenes. EUNSA, Pamplona, 2001, p. 83-84.) 
categoria da co-humanidade de cada indivíduo". A dignidade da pessoa, portanto, deve ser considerada, além da sua própria natureza, na relação com outros indivíduos, em que há uma obrigação geral de respeito ao outro, em razão do seu valor intrínseco como pessoa, que é "retratado num conjunto de direitos e deveres que correspondem à concepção aberta, complexa e heterogênea dos direitos e deveres fundamentais da pessoa humana na sociedade e no Estado contemporâneo", em busca do crescimento e desenvolvimento do indivíduo. ${ }^{13}$

Nas palavras de Ingo Wolfgang Sarlet:

O que se percebe, em última análise, é que onde não houver respeito pela vida e pela integridade física e moral do ser humano, onde as condições mínimas para uma existência digna não forem asseguradas, onde não houver limitação do poder, enfim, onde a liberdade e a autonomia, a igualdade (em direitos e dignidade) e os direitos fundamentais não forem reconhecidos e minimamente assegurados, não haverá espaço para a dignidade da pessoa humana e esta (a pessoa), por sua vez, poderá não passar de mero objeto de arbítrio e injustiças. ${ }^{14}$ (grifou-se)

Adignidade, por ser uma qualidade intrínseca da pessoa, acha-se irrenunciável e inalienável, devendo ser reconhecida, respeitada, promovida e protegida, especialmente quando se trata de conflitos intersubjetivos, pois o ambiente de conflitividade que sucedem nos relacionamentos entre indivíduos é um universo em que se percebe a violação à dignidade da pessoa. Por constituir atributo intrínseco do ser humano e expressar o seu valor absoluto, a dignidade não pode ser objeto de desconsideração e desrespeito, inclusive no tratamento ao conflito. ${ }^{15}$

O Direito como protetor da ordem jurídica e, portanto, da dignidade humana, deve, quando possível, evitar violações e/ou reduzir as consequências das crises relacionais que se verificam no trato social. Para tanto, propõe-se que os conflitos intersubjetivos sejam tratados de maneira adequada, mediante técnicas autocompositivas.

Diante de um conflito, independentemente de sua natureza, deve-se zelar para que "todos recebam igual (já que todos são iguais em dignidade) consideração e respeito por parte do Estado e da comunidade"16, e, neste sentido, o tratamento adequado aos conflitos de interesses, é instrumento de efetivação dos direitos fundamentais, pois, promove a dignidade vez que concede autonomia e liberdade aos indivíduos, esclarecendo os interesses mediatos e imediatos, com o restabelecimento do diálogo entre as partes (principalmente por meio da escuta ativa), incentiva a conservação das relações quando continuadas, como forma de se alcançar a solução do conflito e, acima de tudo,

13 SARLET, Ingo Wolfgang. As Dimensões Da Dignidade Da Pessoa Humana: Construindo Uma Compreensão Jurídico-Constitucional Necessária E Possível. Revista Brasileira de Direito Constitucional. n. 09, jan/jun, 2007, p. 371 .

14 SARLET, Ingo Wolfgang. As Dimensões Da Dignidade Da Pessoa Humana: Construindo Uma Compreensão Jurídico-Constitucional Necessária E Possível. Revista Brasileira de Direito Constitucional. n. 09, jan/jun, 2007, p. 380-381.

15 SARLET, Ingo Wolfgang. As Dimensões Da Dignidade Da Pessoa Humana: Construindo Uma Compreensão Jurídico-Constitucional Necessária E Possível. Revista Brasileira de Direito Constitucional n. 09, jan/jun, 2007, p. 366-367.

16 SARLET, Ingo Wolfgang. As Dimensões Da Dignidade Da Pessoa Humana: Construindo Uma Compreensão Jurídico-Constitucional Necessária E Possível. Revista Brasileira de Direito Constitucional. n. 09, jan/jun, 2007, p. 371 . 
humanizar os tempos de crise.

Em uma sociedade líquida, portanto, os valores da pós-modernidade suprimem "a consciência da alteridade e a capacidade de se compreender o outro na sua própria pluralidade de significados e vivências" ${ }^{17}$, assim, restando apenas a individualidade, a tendência é que os conflitos cresçam exponencialmente. Dessa forma, verifica-se a relevância do tema para o Direito, que como ciência social, tem por objeto o estudo do indivíduo inserido em sociedade em suas relações.

\section{DIREITO FUNDAMENTAL E A DIGNIDADE HUMANA}

Para a compreensão dos conflitos intersubjetivos na contemporaneidade e a resposta adequada do Direito diante estes conflitos, faz-se necessário uma análise dos direitos fundamentais, especificamente por se tratar de alicerce de todo o ordenamento jurídico. A dignidade humana, enfoque no presente trabalho, é um direito pessoal e intransferível que é inerente à pessoa humana, e, para tê-la protegida, no caso de conflitos, faz-se necessário um tratamento adequado, propondo-se no presente estudo a utilização da mediação para proteger a personalidade e promover a dignidade da pessoa.

A noção de direitos fundamentais procede do amadurecimento da própria sociedade. A expressão "direito fundamental" surgiu na França, no século XVIII e decorre de um processo de natureza política e cultural que conduziu à criação da Declaração dos Direitos do Homem e do Cidadão, em 1789. ${ }^{18}$ De acordo com Sidney Guerra, citando o autor Antonio-Enrique Perez Luño ${ }^{19}$, entende-se direitos fundamentais como um conjunto de "faculdades e instituições que, em cada momento histórico, concretizam as exigências da dignidade, da liberdade, da igualdade humana" e que, na atualidade, são reconhecidas nos ordenamentos jurídicos nacionais e internacionais. ${ }^{20}$

Compreender a história dos direitos fundamentais também é estudar o surgimento do Estado constitucional, que tem como essência o reconhecimento e a proteção da dignidade da pessoa humana. ${ }^{21}$ As noções de dignidade, liberdade e igualdade possuem suas raízes na filosofia clássica, em especial na cultura greco-romana, particularmente com o pensamento estoico, desenvolvido por Zenão de Cítio, que foi o primeiro a reconhecer os ideais de igualdade natural dos homens. ${ }^{22}$ Também, as noções de dignidade, liberdade e igualdade têm traços da doutrina cristã, em que se entende que o homem é feito à imagem e semelhança de Deus e, portanto, possui os atributos de dignidade, liberdade e igualdade. Assim, a união entre a concepção greco-romana e 17 GIMENEZ, Charlise Paula Colet. DEL'OLMO, Florisbal, de Souza. ANGELIN, Rosângela. DOS DIREITOS HUMANOS E DOS CONFLITOS NA SOCIEDADE LÍQUIDA PÓS-MODERNA. Revista do Programa de PósGraduação em Direito da UFC. v. 37, n. 2, 2017, p. 267.

18 MORAES, Alexandre de. Direitos humanos fundamentais. São Paulo: atlas, 1997, p. 19: “os direitos humanos fundamentais, em sua concepção atualmente conhecida, surgiram como produto da fusão de várias fontes, desde tradições arraigadas nas diversas civilizações, até a conjugação dos pensamentos filosófico-jurídicos, das ideias com o cristianismo e com o direito natural.” Apud GUERRA, Sidney. Direitos Humanos: curso elementar. 5 ed. São Paulo: Saraiva, 2017, p. 48.

19 LUÑ், Antonio-Enrique Pérez. Derechos humanos, Estado de derecho y Constitución. 5 ed. Madrid: Tecnos, 1995 , p. $46-47$.

20 GUERRA, Sidney. Direitos Humanos: curso elementar. 4 ed. São Paulo: Saraiva, 2017, p. 49-50.

21 SARLET, Ingo Wolfgang. A eficácia dos direitos fundamentais. 12 ed. rev. atual e ampl. Porto Alegre: Livraria do Advogado Editora, 2015, p. 36.

22 FERMENTÃO, Cleide Aparecida Gomes Rodrigues; LIMA, Paulo Gomes Júnior. A EFICÁCIA DO DIREITO Á DIGNIDADE DA PESSOA HUMANA. Revista Jurídica CESUMAR - Mestrado, v. 12, p. 313-340, 2012 , p. 319. 
o cristianismo, deu azo à compreensão de unidade da humanidade e igualdade de todos os homens em dignidade. ${ }^{23}$

Na Idade Média, com o pensamento de São Tomás de Aquino, descrito na obra Summa Teológica, pela primeira vez usou-se a palavra dignetas humanas, tornando evidente o reconhecimento do valor fundamental da dignidade humana em virtude da criação do homem, sendo este imagem e semelhança de Deus. ${ }^{24}{ }^{25}$ Ainda, Pico Della Mirandola, que teve como base a escola tomista, no período renascentista humanista, sustentou que a personalidade humana tem valor próprio, é inata e se expressa na dignidade do ser humano. ${ }^{26}$

No período do humanismo, com a filosofia humanista, o homem teve seu ápice. Segundo Immanuel Kant, o homem é compreendido como um ser dotado em dignidade em razão de sua moralidade e, diferentemente das coisas que possuem preço, o homem possui dignidade, pois é um fim em si mesmo. ${ }^{27}$ Especificamente, são as ideias de Kant que definem, até os dias atuais, a noção de dignidade.

O filósofo descreve que todas as coisas ou têm preço ou dignidade, e aquilo que tem preço, justamente por ser auferível seu valor, pode ser substituída por qualquer outra coisa equivalente, com mesmo preço. $\mathrm{O}$ mesmo não ocorre, entretanto, com a dignidade, já que não há essa relação de equivalência. Para Kant, a humanidade do homem e moralidade são dotadas de dignidade e não preço. ${ }^{28}$

Com o surgimento dos estados totalitários, o advento da $2^{\text {a }}$ Guerra Mundial e as atrocidades realizadas nos períodos de guerras, a noção de dignidade humana ressurgiu, dessa forma, como um combate a esses estados, e tornou-se o principal fundamento do Estado Democrático de Direito. Assim, em virtude das consequências da Segunda Guerra, os países se uniram, e, em 1948 criaram a Declaração dos Direitos Humanos que incorporou a ideia de dignidade da pessoa humana, estabelecendo-a como fundamento de outros direitos, tais como direito à vida, liberdade, integridade. Logo, a proteção ao ser humano passou a ser considerada como o valor principal de toda a ordem jurídica. ${ }^{29}$

A Declaração Universal dos direitos do homem foi parâmetro para a Constituição Federal $^{30}$, promulgada em 1988. Esta assegurou a dignidade humana como princípio e valor

23 SARLET, Ingo Wolfgang. A eficácia dos direitos fundamentais. 12 ed. rev. atual e ampl. Porto Alegre: Livraria do Advogado Editora, 2015, p. 38.

24 SARLET, Ingo Wolfgang. A eficácia dos direitos fundamentais. 4 ed. rev. atual. e ampl. Porto Alegre: Livraria do Advogado, Editora, 2004. p. 111.

25 AQUINO, Tomás. Suma teológica. 2. ed. Tradução Alexandre Correia. Caxias do Sul, RS: Escola Superior de Teologia São Lourenço de Brindes; Caxias do Sul, RS: Ed. UCS, Sutina, 1980. v. L.

26 SARLET, Ingo Wolfgang. A eficácia dos direitos fundamentais. 12 ed. rev. atual e ampl. Porto Alegre: Livraria do Advogado Editora, 2015, p. 38.

27 KANT, Immanuel. Grundlegung zur Metaphysik der Sitten. Tradução Paulo Quintela: Fundamentação da metafísica dos costumes. Edições 70, 2007. p. 77-78.

28 KANT, Immanuel. Grundlegung zur Metaphysik der Sitten. Tradução Paulo Quintela: Fundamentação da metafísica dos costumes. Edições 70, 2007. p. 77-78.

29 LEMOS, Rafael Diogo Diógenes. A dignidade da pessoa humana: conteúdo, limites e possibilidades. Rev. Disc. Jur. Campo Mourão, v. 4, n. 2, ago./dez. 2008, p. 47.

30 Art. $1^{\circ}$ A República Federativa do Brasil, formada pela união indissolúvel dos Estados e Municípios e do Distrito Federal, constitui-se em Estado Democrático de Direito e tem como fundamentos: III - a dignidade da pessoa humana; (BRASIL. Constituição (1988). Constituição da República Federativa do Brasil. Brasília, DF: Senado, 
fundamental, servindo de paradigma de interpretação para todo o ordenamento jurídico brasileiro. Sendo assim, toda norma que viola direta ou indiretamente a dignidade da pessoa humana, viola diretamente os direitos fundamentais previstos na Constituição Federal.

Alexandre de Moraes define o princípio da dignidade humana como o

[...] valor espiritual e moral inerente a pessoa, que se manifesta singularmente na autodeterminação consciente e responsável da própria vida e que traz consigo a pretensão ao respeito por parte das demais pessoas, constituindo-se um mínimo invulnerável que todo estatuto jurídico deve assegurar, de modo que, somente excepcionalmente, possam ser feitas limitações ao exercício dos direitos fundamentais, mas sempre sem menosprezar a necessária estima que merecem todas as pessoas enquanto seres humanos. ${ }^{31}$

O jurista Ingo Wolfgang Sarlet retrata o princípio da dignidade humana como:

[...] a qualidade intrínseca e distintiva reconhecida em cada ser humano que o faz merecedor do mesmo respeito e consideração por parte do Estado e da comunidade, implicando, neste sentido, um complexo de direitos e deveres fundamentais que assegurem a pessoa tanto contra todo e qualquer ato de cunho degradante e desumano, como venham a the garantir condições existenciais mínimas para uma vida saudável, além de propiciar e promover sua participação ativa e co-responsável nos destinos da própria existência da vida em comunhão com os demais seres humanos. ${ }^{32}$

O reconhecimento e a proteção da dignidade humana, para o Direito, resultaram de um avanço na compreensão e reconhecimento do que é a pessoa, de sua personalidade e os valores que lhe são inerentes. ${ }^{33}$

\section{A MEDIAÇÃO COMO INSTRUMENTO DE TRATAMENTO ADEQUADO AOS CONFLITOS DE INTERESSES PARA A PROTEÇÃO DA PESSOA E PROMOÇÃO DA DIGNIDADE HUMANA}

A mediação é um instrumento de tratamento aos conflitos, para a sua eficácia faz-se preciso um ambiente de crescimento e transformação social, sendo necessário um tratamento adequado,

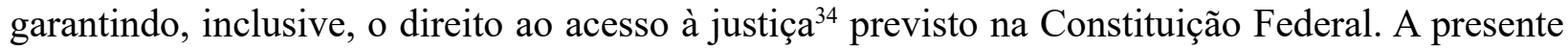
pesquisa propõe-se ao estudo, ainda que geral, dos meios consensuais (autocompositivos) como

1988.)

31 MORAES, de Alexandre. Direitos humanos fundamentais. 4.ed. São Paulo: Atlas, 2002, p. 60.

32 SARLET, Ingo Wolfgang. As Dimensões Da Dignidade Da Pessoa Humana: Construindo Uma Compreensão Jurídico-Constitucional Necessária E Possível. Revista Brasileira de Direito Constitucional. n. 09, jan./jun., 2007, p. 383.

33 SARLET, Ingo Wolfgang. As Dimensões Da Dignidade Da Pessoa Humana: Construindo Uma Compreensão Jurídico-Constitucional Necessária E Possível. Revista Brasileira de Direito Constitucional. n. 09, jan/jun, 2007, p. 362 .

34 "O cerne do acesso à justiça não é possibilitar que todos possam ir à corte, mas, sim, que a justiça possa ser realizada no contexto em que se inserem as partes, com a salvaguarda da imparcialidade de decisão e da igualdade efetiva das partes." (PEDROSO, João; TRINCÃO, Catarina; DIAS, João Paulo. E a justiça aqui tão perto? As transformações no acesso ao direito e à justiça. Disponível em: <https://www.oa.pt/Uploads/\%7B3CF0C3FA-D7EF-4CDE-B784C2CACEE5DB48\%7D.doc $>$. Acesso em: 23 abr. 2018 Apud TARTUCE, Fernanda. Mediação nos conflitos civis. Rio de Janeiro: Forense. São Paulo: Método, 2018, p. 97) 
forma de humanização das crises relacionais.

O Código de Processo Civil de 2015 trouxe em seu conteúdo, como norma fundamental ${ }^{35}$, a ideia de que para se alcançar a pacificação social, o processo judicial é um dos instrumentos existentes, dentre muitos outros caminhos que se pode tomar na busca pela solução adequada ao conflito. ${ }^{36}{ }^{37}$ Nesse sentido, a pacificação social pode se dar pela via da heterocomposição ${ }^{38}$, em que um terceiro é quem decide a respeito do litígio, servindo como exemplo o processo judicial e a arbitragem, e a autocomposição, em que as próprias partes envolvidas no conflito, com o auxílio de um terceiro capacitado, por meio de técnicas interdisciplinares, alcançam a compreensão do conflito como uma oportunidade de promoção e desenvolvimento da dignidade humana, colaborando com toda a instituição e Poder Judiciário. ${ }^{39}$

Nota-se o crescimento do interesse de novas técnicas de tratamento de conflitos, diante do crescimento da pesquisa jurídica, incentivos por parte dos Tribunais e Conselho Nacional de Justiça e, inclusive, com a obrigatoriedade da matéria de conciliação, mediação e arbitragem constar nas grades curriculares dos cursos de Direito de todo o país. ${ }^{40}$ Ocorre que antes mesmo de visar a solução do conflito e trazer pacificação às partes, os meios consensuais, em sua maioria, autocompositivos, têm como objetivo a humanização das relações e dos vínculos, especialmente o reconhecimento do outro como pessoa dotada de valores e dignidade.

Num mundo de individualidade, em que tudo está em processo de "liquidez", como Bauman dissera, destacam-se técnicas que têm o viés humano de promover o desenvolvimento pleno da dignidade de cada indivíduo. O Direito deve levar em consideração os ideais modernos e as consequências nas relações, já que seu objeto de estudo é o sujeito que é "ao mesmo tempo psíquico, biológico, físico etc.”41 Assim é o caso da mediação ${ }^{42}$, que como instrumento de 35 Art. $1^{\circ} \mathrm{O}$ processo civil será ordenado, disciplinado e interpretado conforme os valores e as normas fundamentais estabelecidos na Constituição da República Federativa do Brasil, observando-se as disposições deste Código.

$\S 1^{\circ}$ É permitida a arbitragem, na forma da lei.

$\S 2^{\circ}$ O Estado promoverá, sempre que possível, a solução consensual dos conflitos.

$\S 3^{\circ}$ A conciliação, a mediação e outros métodos de solução consensual de conflitos deverão ser estimulados por juízes, advogados, defensores públicos e membros do Ministério Público, inclusive no curso do processo judicial.

(BRASIL, Lei $\mathrm{n}^{\circ} 13.105$, de 16 de março de 2015. Diário Oficial, Brasília, 2015. Disponível em: <http://www. planalto.gov.br/ccivil_03/_ato2015-2018/2015/lei/113105.htm >. Acesso em: 03 abr. 2019)

36 MEDINA, José Miguel Garcia. Direito processual civil moderno. São Paulo: Revista dos Tribunais, 2015. p. 101. 37 NETO, João Luiz Lessa. O NOVO CPC ADOTOU O MODELO MULTIPORTAS!!! E AGORA?!. Revista dos Tribunais. v. 244, jun, 2015, p. 427-428.

38 "Na jurisdição institucionalizada, o juiz é um "terceiro" que dita a solução, através de imperativos concretos (normas jurídicas) dirigidos à conduta das partes processuais. Assim, a jurisdição não administra os conflitos apresentados, pois utiliza uma sutileza normativa que propõe o deslocamento da conflitividade (sentimento de insatisfação), reinstitucionalizando o conflito através da jurisdicionalização da insatisfação pessoal do sujeito em um fato litigioso quantificável ao imprimir-lhe a necessária decidibilidade: esquece-se das insatisfações e do retorno à harmonia entre indivíduos para tratar de algarismos racionais, ou melhor, cifras. "Por consequência, o direito não decide o conflito; decide o que ele reinstitucionaliza como conflito, ou seja, o 'conflito jurídico'. Não julga o fato; julga o "fato jurídico", o litígio." BISOL, Jairo. "Mediação e modernidade:sítios para uma reflexão hermenêutica". Apud WARAT, Luis Alberto (Org). Em nome do acordo: a mediação no direito, p. 112. Apud MENDONÇA, Rafael. (Trans)modernidade e mediação de conflitos. 1 ed. Rio de Janeiro: KBR Editora Digital Ltda, 2012.

39 TARTUCE, Fernanda. Mediação nos conflitos civis. Rio de Janeiro: Forense. São Paulo: Método, 2018, p. 188 40 "As disciplinas que versem sobre conciliação, mediação e arbitragem passam a ser matérias obrigatórias nas grades curriculares dos cursos de direito de todo o país, segundo a Resolução CNE/CES n. 5/2018, oriunda do Parecer $n^{\circ}$ 635/2018, homologado pela Portaria no 1.351/2018 do Ministério da Educação (MEC)." (CONSELHO NACIONAL DE JUSTIÇA. Conciliação será matéria obrigatória nos cursos de direito. Disponível em: $<\mathrm{http}: / / \mathrm{www} . c n j . j u s$.

br/noticias/cnj/88448-conciliacao-sera-materia-obrigatoria-nos-cursos-de-direito >. Acesso em: 03 abr. 2019.)

41 MENDONÇA, Rafael. (Trans)modernidade e mediação de conflitos. 1 ed. Rio de Janeiro: KBR Editora Digital Ltda, 2012.

42 Por Mediação de Conflitos se entende o método não-adversarial de conhecimento e resolução de conflitos, 
humanização de conflitos, ganhou destaque nas práticas autocompositivas.

As origens da mediação de conflitos remontam à antiguidade, estando presente em diversas culturas. Especificamente, em Roma já havia o procedimento denominado in iudicio, que acontecida diante o mediador ou árbitro. Na cultura judaica, chinesa e japonesa, a mediação esteve presente, sendo que na China a prática da mediação adveio dos ensinamentos de Confúcio. ${ }^{43}$ Nos Estados Unidos da América, a mediação é aplicada há mais de 30 anos com o "Program on Negotiation at Harvard Law School” (Programa de Negociação da Harvard Escola de Direito). ${ }^{44}$

No Brasil, a mediação surgiu em um movimento que além da busca pela diminuição dos números de processos no Poder Judiciário, buscou a solução consensual, pacificação entre os indivíduos e humanização do conflito, promovendo, assim, a dignidade humana e a proteção à existência humana. Em 2010, o Conselho Nacional de Justiça editou a Resolução de $n^{\circ} 125$ de $2010^{45}$, que dispôs sobre a Política Judiciária Nacional de tratamento adequado dos conflitos de interesses no âmbito do Poder Judiciário ${ }^{46}$. A Resolução revelou-se como o primeiro passo em direção de uma cultura adequada à nova realidade de conflitos intersubjetivos, em que as partes podem participar como protagonistas e influenciar nas transformações das crises em oportunidades de desenvolvimento e crescimento. ${ }^{47}$

Em 2015, com a entrada em vigor da Lei da Mediação (Lei n. 13.140), houve a regulamentação pormenorizadamente da profissão e do exercício da conciliação e mediação judicial e extrajudicial. ${ }^{48}$ Os projetos do Conselho Nacional de Justiça (CNJ) e dos Tribunais bem como o avanço legislativo da matéria, demonstram a tendência do sistema jurídico brasileiro ao incentivo de meios autocompositivos de tratamento de conflitos, especialmente a mediação, que ecoa positivamente na sociedade atual, pois estas técnicas consideram o indivíduo em sua dimensão uma práxis filosófica diferenciada que permite aos sujeitos um olhar para novos rumos, possibilitando acesso a condições de autogestão das experiências, emancipados de muitos preceitos adquiridos durante o período moderno. (MENDONÇA, Rafael. (Trans)modernidade e mediação de conflitos. 1 ed. Rio de Janeiro: KBR Editora Digital Ltda, 2012.)

43 CACHAPUZ, Rozane da Rosa. Mediação nos conflitos e Direito de Família. Curitiba: Juruá, 2005, p. 34 Apud CACHAPUZ, Rozane da Rosa, GOMES, Taritha Meda Caetano. A mediação como instrumento pacificador nos conflitos familiares. SCIENTIA IURIS, Londrina, v. 10, 2006, p. 277.

44 "O Programa de Negociação (PON) é um programa entre a Universidade de Harvard, Instituto Tecnológico de Massachusetts e Universidade Tufts, e serve como um centro de pesquisa interdisciplinar dedicado ao desenvolvimento da teoria e prática de negociação e resolução de conflitos nos setores públicos e privados. A missão da PON inclui fomentar a próxima geração de professores e acadêmicos de negociação, ajudando os alunos a se tornarem negociadores mais eficazes e proporcionando um fórum para a discussão de ideias. [Tradução livre]. (HARVARD LAW SCHOOL. Program on negotiation. Disponível em: <https://www.pon.harvard.edu/>. Acesso em: 03 abr. 2019)

45 CONSELHO NACIONAL DE JUSTIÇA, Resolução No 125 de 29/11/2010. Disponível em: < http://www.cnj.jus.

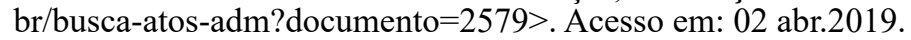

46 "A referida Resolução estabeleceu pela primeira vez a estrutura e os procedimentos para o encaminhamento das partes para a conciliação e a mediação, permitindo a criação de núcleos de atendimento à população que busque uma solução para seus conflitos. Nesses núcleos, que são órgãos administrativos dos Tribunais, os cidadãos poderiam ser direcionados para a conciliação ou a mediação pré-processuais, para a conciliação ou a mediação em processos judiciais já existentes, ou ainda, poderiam ser conduzidos ao órgão competente, quando a questão estivesse fora das suas atribuições. Ainda segundo a Resolução, todos os Estados da Federação devem implementar núcleos permanentes de métodos consensuais de soluções de conflitos nos seus Tribunais, responsáveis por coordenar e instalar centros judiciários com esse objetivo, aproximando o Judiciário dos cidadãos." (COELHO, Renata Moritz Serpa. ATUALIDADES SOBRE A MEDIAÇÃO DE CONFLITOS NO BRASIL A PARTIR DE 2015. Revista dos Tribunais. vol. 272, out, 2017, p. 02.)

47 COELHO, Renata Moritz Serpa. ATUALIDADES SOBRE A MEDIAÇÃO DE CONFLITOS NO BRASIL A PARTIR DE 2015. Revista dos Tribunais. vol. 272, out. 2017, p. 02.

48 BRASIL, Lei 13.140 de 26 de junho de 2015. Diário Oficial, Brasília, 2015. Disponível em: <http://www.planalto. gov.br/ccivil_03/_ato2015-2018/2015/lei/113140.htm>. Acesso em: 02 abr. 2019. 
relacional (ser com os outros) e promove o desenvolvimento da pessoa no sentido integral de sua dignidade.

O procedimento de mediação ${ }^{49}$ prima pela informalidade, celeridade, sigilo e o caráter cooperativo entre as partes, no qual o conflito é descaracterizado como algo proeminentemente negativo, demonstrando outro aspecto, que possibilite aos sujeitos, uma vez protagonistas e norteados por profissional capacitado, alcançarem a harmonia em meio ao conflito e, assim, viabilizar o convívio saudável..$^{50} 51$

Dentre as inúmeras técnicas utilizadas no procedimento de mediação, destacam-se as técnicas utilizadas para gestão de conflito, as quais são: o resumo do conflito; a recontextualização ou parafraseamento; a audição de propostas implícitas; a escuta ativa também conhecida como escuta dinâmica, escuta reflexiva e escuta empática; e o enfoque prospectivo, dentre as diversas técnicas que não serão abordadas no presente estudo.

O resumo, trata-se de uma técnica em que o mediador, após ouvir as partes, faz um resumo de toda a situação apresentada até então, identificando as questões a serem discutidas e demonstrando os interesses de cada indivíduo, utilizando uma linguagem positiva e neutra. Mostra-se como instrumento eficaz no processo de mediação, pois dá um norte ao procedimento e, sobretudo, centraliza a discussão nos principais aspectos do conflito. ${ }^{52}$ Nesse sentido, o resumo contribui às partes, pois deixa claro aos indivíduos os reais interesses de cada uma das partes.

A recontextualização ou parafraseamento consiste em uma técnica em que as partes podem ter uma nova perspectiva da controvérsia, pois o facilitador irá apresentar as alegações feitas por cada uma das partes, todavia, em uma nova perspectiva, mais clara e compreensível, com enfoque prospectivo, voltado às soluções, filtrando os componentes negativos, com o objetivo de encaixar essa informação no processo de modo construtivo. ${ }^{53}$

Durante o conflito, a comunicação das partes acha-se comprometida. Assim, a audição de propostas implícitas é um instrumento capaz de esclarecer as propostas que as partes fazem, mas em virtude das emoções envolvidas, não são exploradas. Nesse sentido,

As partes de uma disputa muitas vezes em razão de se encontrarem em um estado de ânimos exaltado têm dificuldade de se comunicar em uma linguagem neutra e eficiente. Como resultado dessa comunicação ineficiente, as partes normalmente propõem soluções sem perceber que, de fato, estão fazendo isso. ${ }^{54}$

49 Consoante WARAT, "a mediação seria uma proposta transformadora do conflito porque não busca a sua decisão por um terceiro, mas, sim, a sua resolução pelas próprias partes, que recebem auxílio do mediador para administrálo. A mediação não se preocupa com o litígio, ou seja, com a verdade formal contida nos autos. Tampouco, tem como única finalidade a obtenção de um acordo." (WARAT, Luis Alberto. O Ofício do Mediador. Habitus, 2001).

50 ALMEIDA, Mariana Amaro Theodoro. A MEDIAÇÃO DOS CONFLITOS DE FAMÍLIACOMO INSTRUMENTO DE CONCRETIZAÇÃO DA FRATERNIDADE. Revista de Direito de Família e das Sucessões. vol. 6, out./dez, 2015, pág. 02, 08.

51 MUZSKAT, Malvina Ester. Mediação de Conflitos: pacificando e prevenindo a violência. São Paulo: Summus, 2003.

52 CONSElHO NACIONAL DE JUSTIÇA. Azevedo, André Gomma de (Org.). Manual de Mediação Judicial. 6. ed. Brasília: CNJ, 2016, p. 150, 178. Disponível em: <http://www.cnj.jus.br/files/conteudo/arquivo/2016/07/ f247f5ce60df2774c59d6e2dddbfec54.pdf>. Acesso em: 03 abr. 2019.

53 CONSELHO NACIONAL DE JUSTIÇA. Azevedo, André Gomma de (Org.). Manual de Mediação Judicial. 6. ed. Brasília: CNJ, 2016, p. 209. Disponível em: <http://www.cnj.jus.br/files/conteudo/arquivo/2016/07/ f247f5ce60df2774c59d6e2dddbfec54.pdf>. Acesso em: 03 abr. 2019.

54 CONSElHO NACIONAL DE JUSTIÇA. Azevedo, André Gomma de (Org.). Manual de Mediação Judicial.

6. ed. Brasília: CNJ, 2016, p. 234. Disponível em: <http://www.cnj.jus.br/files/conteudo/arquivo/2016/07/ 
A escuta ativa ou escuta dinâmica é uma das técnicas utilizadas para incentivar a comunicação e facilitar a dinâmica entre as partes em conflito. Como técnica aplicada na mediação, a escuta dinâmica auxilia na construção da confiança e respeito, pois permite que as partes expressem suas emoções e opiniões, num ambiente seguro e propício. Na escuta ativa o mediador, que deve participar de forma ativa da conversa entre as partes, mostrando-se receptivo para escutar, sem julgamentos.

Carlos Eduardo de Vasconcelos explica que na escuta ativa,

O mediador sabe que, por mais que tudo pareça pronto para que as pessoas cheguem a um acordo, algo muito significativo pode estar guardado, omitido. As pessoas não se entendem sem terem sido efetivamente escutadas. As pessoas precisam dizer o que sentem e, na mediação, esta pode ser a primeira vez que isto está sendo possível. ${ }^{55}$

O que diferencia a escuta ativa para o simples ato de ouvir alguém é que na técnica, confere-se importância ao interlocutor, à parte que fala, pois ela é merecedora de respeito e atenção. O mediador William Ury explica que comumente, ouve-se o que os outros têm a dizer tomando como base o que já se entende a respeito de determinado assunto. A escuta dinâmica, ao contrário, proporciona que se ouça alguém a partir do ponto de vista do sujeito que fala $\mathrm{E}$ não de quem o ouve. ${ }^{56} \mathrm{~A}$ escuta ativa, dessa forma, na perspectiva das partes, propicia que os conflitantes ouçam o que o outro tem a dizer, sem interrupções, incentivando o respeito mútuo, vez que se considera o outro como é, incentivando na humanização do conflito.

$\mathrm{O}$ enfoque prospectivo relaciona-se à visão da situação conflituosa que as partes têm em que uma considera-se certa em detrimento da outra. O mediador, nesta técnica, tem o papel de demonstrar aos indivíduos que é possível a busca de soluções em conjunto (enfoque prospectivo), sem a investigação de culpados (enfoque retrospectivo), descartando os fatos que não tenham uma "participação eficiente ou relevante para a boa resolução da disputa". O objetivo da técnica é que por meio do enfoque voltado ao futuro, as partes passem "a se compreender mutuamente e a perceber que seus interesses podem ser convergentes". ${ }^{57}$

Com a análise dos itens acima, o que se compreende, portanto, é que as técnicas aplicadas na mediação têm um objetivo em comum: reconhecimento do indivíduo como pessoa dotada de valores e humanização do conflito, pois estas e as demais técnicas aplicadas incentivam a diminuição do sentimento de rivalidade e a construção do discernimento que a solução ao conflito, quando este for mediavel, é alcançada em conjunto.

\footnotetext{
f247f5ce60df2774c59d6e2dddbfec54.pdf>. Acesso em: 03 abr. 2019.

55 VASCONCELOS, Carlos Eduardo. Mediação de conflitos e práticas restaurativas. 5. ed. ver., atual. e ampl. Rio de janeiro: Forense; São Paulo: Método, 2017, p. 163-164.

56 URY, William. Como chegar ao sim com você mesmo. Tradução de Afonso Celso da Cunha. Rio de Janeiro: Sextante, 2015, p. 94.

57 CONSELHO NACIONAL DE JUSTIÇA. Azevedo, André Gomma de (Org.). Manual de Mediação Judicial. 6. ed. Brasília: CNJ, 2016, p. 186. Disponível em: <http://www.cnj.jus.br/files/conteudo/arquivo/2016/07/ f247f5ce60df2774c59d6e2dddbfec54.pdf>. Acesso em: 03 abr. 2019.
} 


\section{CONSIDERAÇÕES FINAIS}

O princípio da dignidade da pessoa humana, fundamento de todo ordenamento jurídico, considera a pessoa humana como um ser em si mesmo e um ser que se constrói na relação com outros indivíduos. Assim, a dignidade possui uma dimensão individual e relacional. Em seu segundo aspecto, tal direito (dignidade) deve ser resguardado na relação com outras pessoas. O conflito, portanto, se não tratado adequadamente, acha-se como instrumento de violação da dignidade humana.

A pós-modernidade destaca-se pela exacerbada individualidade e pela noção de que tudo é passageiro e substituível, inclusive os relacionamentos. Por essa razão, os conflitos entre pessoas tendem a aumentar, uma vez que num relacionamento em crise, um indivíduo não leva em consideração os valores e a dignidade que o outro tem, violando assim, o fundamento de todo o ordenamento jurídico, a dignidade humana.

Em virtude desta crise social, o tratamento ao conflito que ocorre na via judicial, por si só, em determinados casos, não proporciona aos indivíduos a resolução do conflito (quando a relação for pontual) nem a continuidade dos vínculos (quando se trata de relações continuadas).

No presente trabalho, portanto, propôs-se o uso da mediação como forma de tratamento adequado a estes conflitos de interesses, visando a humanização das crises e resolução das controvérsias, vez que o procedimento da mediação leva em consideração aspectos do conflito que a via judicial não tem o condão de analisar, e que, numa relação conflituosa, violam a dignidade do outro.

Busca-se, portanto, o incentivo na utilização da mediação e das técnicas integrantes ao procedimento que proporcionam às partes momentos de reflexão, tais como: o resumo do conflito; a recontextualização ou parafraseamento; a audição de propostas implícitas; a escuta ativa também conhecida como escuta dinâmica, escuta reflexiva e escuta empática; e o enfoque prospectivo, como forma de promoção da dignidade humana.

\section{REFERÊNCIAS BIBLIOGRÁFICAS}

\section{ALMEIDA, Mariana Amaro Theodoro. A MEDIAÇÃO DOS CONFLITOS DE FAMÍLIA COMO INSTRUMENTO DE CONCRETIZAÇÃO DA FRATERNIDADE. Revista de Direito de Família e das Sucessões. vol. 6, p. 175-193, out./dez., 2015.}

AQUINO, Tomás. Suma teológica. 2. ed. Tradução Alexandre Correia. Caxias do Sul, RS: Escola Superior de Teologia São Lourenço de Brindes; Caxias do Sul, RS: Ed. UCS, Sutina, 1980. v. L.

ARELlanO, J. Ferrer. Eı Misterio de los Orígenes. EUNSA, Pamplona, 2001.

BAUMAN, Zygmunt. Identidade. Rio de Janeiro: Zahar, 2005.

BAUMAN, Zygmunt. Vida líquida. Rio de Janeiro: Zahar, 2009, p. 7. Apud GORETTI, Ricardo. Mediação e acesso à justiça. Salvador: Editora JusPodivm, 2016. 
BRASIL, Lei 13.140 de 26 de junho de 2015. Diário Oficial, Brasília, 2015. Disponível em: $<$ http://www.planalto.gov.br/ccivil_03/_ato2015-2018/2015/lei/113140.htm>. Acesso em: 02 abr. 2019

BRASIL, Lei n ${ }^{\circ}$ 13.105, de 16 de março de 2015. Diário Oficial, Brasília, 2015. Disponível em: $<$ http://www.planalto.gov.br/ccivil_03/_ato2015-2018/2015/lei/113105.htm>. Acesso em: 03 abr. 2019

BRASIL. Constituição (1988). Constituição da República Federativa do Brasil. Brasília, DF: Senado, 1988.

CACHAPUZ, Rozane da Rosa. Mediação nos conflitos e Direito de Família. Curitiba: Juruá, 2005 Apud CACHAPUZ, Rozane da Rosa, GOMES, Taritha Meda Caetano. A mediação como instrumento pacificador nos conflitos familiares. SCIENTIA IURIS, Londrina, v. 10, p. 271286, 2006.

COELHO, Renata Moritz Serpa. ATUALIDADES SOBRE A MEDIAÇÃO DE CONFLITOS NO BRASIL A PARTIR DE 2015. Revista dos Tribunais. vol. 272, out., 2017.

CONSELHO NACIONAL DE JUSTIÇA, Resolução No 125 de 29/11/2010. Disponível em: $<$ http://www.cnj.jus.br/busca-atos-adm?documento=2579>. Acesso em: 02 abr. 2019.

CONSELHO NACIONAL DE JUSTIÇA. Azevedo, André Gomma de (Org.). Manual de Mediação Judicial. 6. ed. Brasília: CNJ, 2016. Disponível em: <http://www.cnj.jus.br/files/ conteudo/arquivo/2016/07/f247f5ce60df2774c59d6e2dddbfec54.pdf>. Acesso em: 03 abr. 2019.

CONSELHO NACIONAL DE JUSTIÇA. Conciliação será matéria obrigatória nos cursos de direito. Disponível em: $<$ http://www.cnj.jus.br/noticias/cnj/88448-conciliacao-sera-materiaobrigatoria-nos-cursos-de-direito $>$. Acesso em: 03 abr. 2019.

DE PLÁCIDO E SILVA, Oscar José. Vocabulário jurídico. 32. ed. Rio de Janeiro: Forense, 2016.

DEUTSCH, Morton. The Resolution of Conflict: Constructive and Destructive Processes. New Haven and London: Yale University Press, 1973.

FERMENTÃO, Cleide Aparecida Gomes Rodrigues; LIMA, Paulo Gomes Júnior. A EFICÁCIA DO DIREITO Á DIGNIDADE DA PESSOA HUMANA. Revista Jurídica CESUMAR -

Mestrado, v. 12, p. 313-340, 2012.

GIMENEZ, Charlise Paula Colet. DEL'OLMO, Florisbal, de Souza. ANGELIN, Rosângela. DOS DIREITOS HUMANOS E DOS CONFLITOS NA SOCIEDADE LÍQUIDA PÓSMODERNA. Revista do Programa de Pós-Graduação em Direito da UFC. v. 37, n. 2, 2017.

GORETTI, Ricardo. Mediação e acesso à justiça. Salvador: Editora JusPodivm, 2016.

GUERRA, Sidney. Direitos Humanos: curso elementar. 4 ed. São Paulo: Saraiva, 2017. 
HARVARD LAW SCHOOL. Program on negotiation. Disponível em: <https://www.pon. harvard.edu/>. Acesso em: 03 abr. 2019

KANT, Immanuel. Grundlegung zur Metaphysik der Sitten. Tradução Paulo Quintela: Fundamentação da metafísica dos costumes. Edições 70, 2007.

LEMOS, Rafael Diogo Diógenes. A dignidade da pessoa humana: conteúdo, limites e possibilidades. Rev. Disc. Jur. Campo Mourão, v. 4, n. 2, p. 41-63, ago./dez., 2008.

LUÑO, Antonio-Enrique Pérez. Derechos humanos, Estado de derecho y Constitución. 5 ed. Madrid: Tecnos, 1995.

MEDINA, José Miguel Garcia. Direito processual civil moderno. São Paulo: Revista dos Tribunais, 2015.

MENDONÇA, Rafael. (Trans)modernidade e mediação de conflitos. 1 ed. Rio de Janeiro: KBR Editora Digital Ltda, 2012.

MORAES, Alexandre de. Direitos humanos fundamentais. São Paulo: Atlas, 1997.

MORAES, de Alexandre. Direitos humanos fundamentais. 4.ed. São Paulo: Atlas, 2002.

MORIN, Edgar. A educação e a complexidade: os setes saberes e outros ensaios. 6 ed. Rio de Janeiro: Cortez, 2013.

MUZSKAT, Malvina Ester. Mediação de Conflitos: pacificando e prevenindo a violência. São Paulo: Summus, 2003.

PEDROSO, João; TRINCÃO, Catarina; DIAS, João Paulo. E a justiça aqui tão perto? As transformações no acesso ao direito e à justiça. Disponível em: <https://www.oa.pt/ Uploads/\%7B3CF0C3FA-D7EF-4CDE-B784-C2CACEE5DB48\%7D.doc $>$. Acesso em: 23 abr. 2018 Apud TARTUCE, Fernanda. Mediação nos conflitos civis. Rio de Janeiro: Forense. São Paulo: Método, 2018.

SARLET, Ingo Wolfgang. A eficácia dos direitos fundamentais. 12 ed. rev. atual e ampl. Porto Alegre: Livraria do Advogado Editora, 2015.

SARLET, Ingo Wolfgang. As Dimensões Da Dignidade Da Pessoa Humana: Construindo Uma Compreensão Jurídico-Constitucional Necessária E Possível. Revista Brasileira de Direito Constitucional. n. 09, jan./jun. 2007.

TARTUCE, Fernanda. Mediação nos conflitos civis. Rio de Janeiro: Forense. São Paulo: Método, 2018.

URY, William. Como chegar ao sim com você mesmo. Tradução de Afonso Celso da Cunha. Rio de Janeiro: Sextante, 2015.

VASCONCELOS, Carlos Eduardo. Mediação de conflitos e práticas restaurativas. 5. ed. ver., atual. e ampl. Rio de janeiro: Forense; São Paulo: Método, 2017. 
Recebido em: 23/10/2019.

Aprovado em: 03/11/2019. 